\title{
GEOQUÍMICA DE METAIS PESADOS EM SEDIMENTOS DO RIO GUAMÁ E DOS PRINCIPAIS CANAIS DE DRENAGEM DE BELÉM, PARÁ, BRASIL.
}

\author{
Fernanda NASCIMENTO ${ }^{1}$, Norbert FENZL ${ }^{2}$
}

RESUMO - As concentrações de $\mathrm{Cr}, \mathrm{Mn}, \mathrm{Fe}, \mathrm{Co}, \mathrm{Ni}, \mathrm{Cu}, \mathrm{Zn}$ e $\mathrm{Pb}$ nas diferentes fases do ambiente sedimentar (trocável, orgânica, redutivel e residual) são analísadas nos sedimentos de fundo dos canais de drenagem mais importantes de Belém - Quintino, Tamandaré, Reduto e Una - e no rio Guamá. Os resultados mostram que a maioria dos metais associa-se preferencialmente à fase residual no rio Guamá e às fases redutivel e residual, no caso dos canais. De um modo geral, os metais $\mathrm{Fe}, \mathrm{Zn}$ e $\mathrm{Pb}$ se associam geralmente à fração redutivel, enquanto $\mathrm{Cu}, \mathrm{Cr}, \mathrm{Mn}$, Co e Ni mostram-se relacionados à fração residual.

Palavras-chave: metais pesados; fases geoquímicas; sedimento de fundo; rio Guamá.

Geochemistry of Heavy Metals in Sediments of the Guama River and Main Drainage Channels of Belém, Pará, Brazil.

ABSTRACT - The concentrations of $\mathrm{Cr}, \mathrm{Mn}, \mathrm{Fe}, \mathrm{Co}, \mathrm{Ni}, \mathrm{Cu}, \mathrm{Zn}$, and $\mathrm{Pb}$ in the main geochemical phases of the sediment (exchangeable, bound to organic matter, bound to Fe-Mn oxides, and residual) were studied in the bottom sediments of the Guama river and the drainage channels (Tamandaré, Quintino, Reduto, and Una) of Belém, Pará. The concentrations of metals in the bottom sediments of the Guama river showed to be associated mainly to residual phase, whereas in the channels they are linked to Fe-Mn oxides and residual phase. Generally, in the analized sediments, the groups of metals $\mathrm{Fe}, \mathrm{Zn}, \mathrm{Pb}$ are showing association with the $\mathrm{Fe}-\mathrm{Mn}$ oxides phase, and $\mathrm{Cu}, \mathrm{Cr}, \mathrm{Mn}, \mathrm{Co}, \mathrm{Ni}$ with residual phase.

Key-words: heavy metals; geochemical phases; bottom sediments; Guamá river.

\section{INTRODUÇÃO}

Belém, a capital do Estado do Pará, situa-se às margens do rio Guamá e da baía do Guajará, a uma altitude em média $15 \mathrm{~m}$ acima do nível do mar. Cerca de $60 \%$ do território compreendido pelo Municipio de Belém é formado por baías, rios, "furos" e igarapés, que são influenciados diariamente pelas marés.

Os igarapés Quintino, Tamandaré, Reduto e Una são atualmente os principais canais de drenagem da maioria dos efluentes líquidos produzidos por uma população de cerca de um milhão de habitantes. $O$ rio
Guamá localiza-se ao sul da cidade, onde se encontra com os rios Acará e Moju, formando a baía do Guajará. Como referência dos valores de background, coletou-se uma amostra na margem do rio contigua a UFPA, a $6 \mathrm{~km}$ a montante dessa confluência (Fig. 1).

O objetivo do trabalho é determinar, através da análise sequencial modificada de TESSIER et al. (1979), os metais de transição $\mathrm{Cr}, \mathrm{Mn}, \mathrm{Fe}, \mathrm{Co}$, $\mathrm{Ni}, \mathrm{Cu}, \mathrm{Zn}$ e $\mathrm{Pb}$ das fases geoquímicas às quais são preferencialmente associados em ambientes aquáticos, (a) trocável, (b) orgânica, (c) redutivel e (d) residual.

Pos-Grad. Centro de Geociências/UFPA, PA.

2 Prof. Pesq. - Centro de Geociencias/UFPA, PA - Campus Universitário do Guamá Caixa Postal 1611, CEP 66075-110, Belém - Pará. 


\section{Área Metropolitana de Belém}

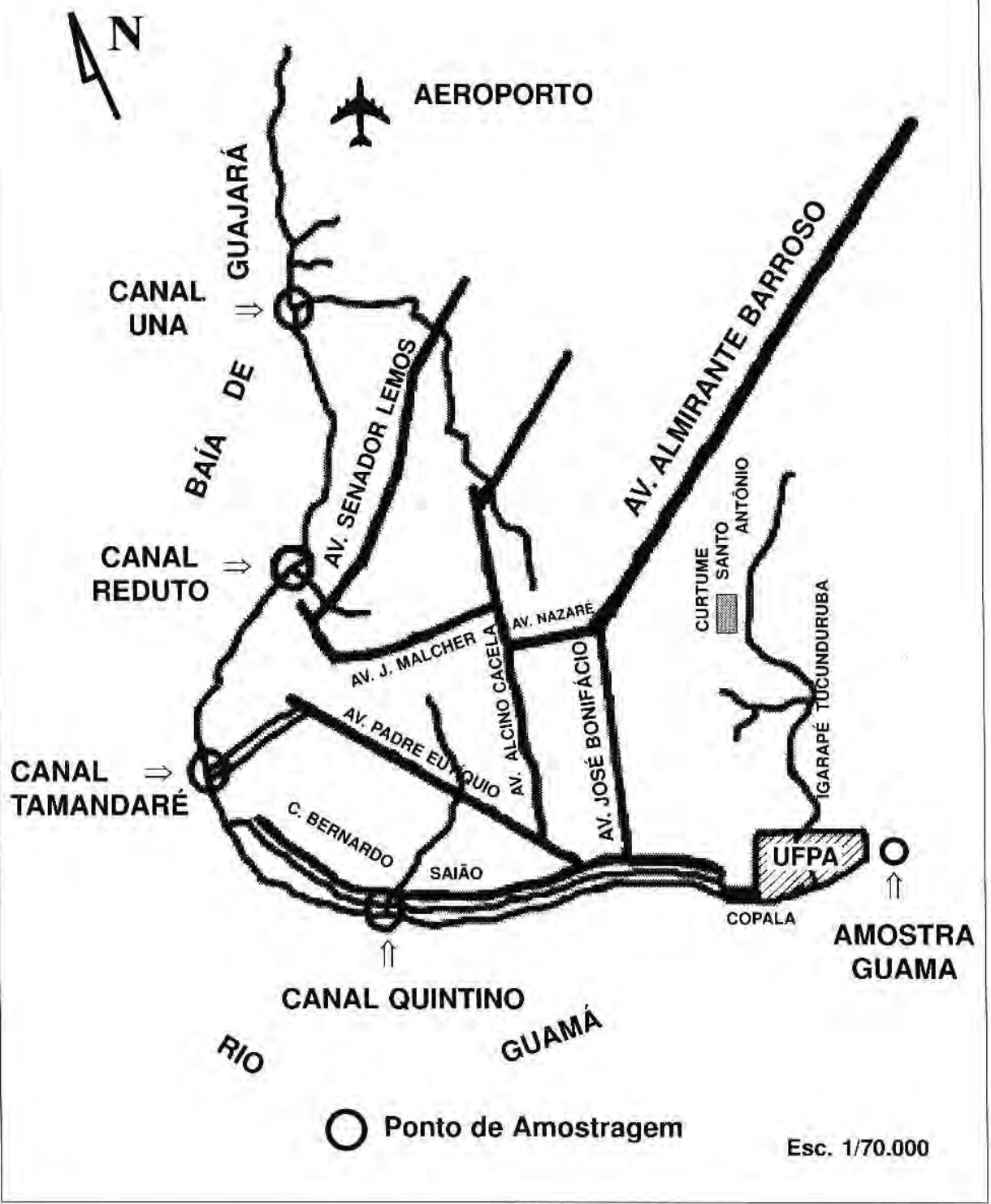

Figura 1. Localização da área do trabalho 
A associação dos metais a estas fases permite deduzir as diversas formas ionicas, as quantidades disponiveis e os meios de transporte dos metais. Um dos objetivos básicos da análise seletiva é de identificar os íns metálicos de origem antropogênica potencialmente tóxicos disponiveis no ambiente (GIBBS, 1977; TESSIER et al., 1979; SOUZA, 1986; LACERDA et al., 1989; OVALLE et al., 1989; JORDÃO et al., 1990; LACERDA et al., 1990).

\section{METODOLOGIA}

\section{COLETA}

Os sedimentos de fundo foram coletados nos quatro principais canais de drenagem Quintino, Tamandaré, Reduto e Una, e no rio Guamá, durante o período de menor precipitação (agosto/ 1993) e no final deste período (novembro/1993) (Fig. 1).

Cerca de $6 \mathrm{~kg}$ de amostra de sedimentos foram tiradas nos primeiros $10 \mathrm{~cm}$ a partir da superfície, em seguida armazenadas em frascos de vidro, protegidas de iluminação, e conservadas a temperatura de $-4^{\circ} \mathrm{C}$ até o laboratório. No laboratório as amostras foram armazenadas a $-25^{\circ} \mathrm{C}$.

\section{TRATAMENTO}

No laboratório as amostras foram submetidas aos seguintes tratamentos:

- homogeneização a úmido;

- peneiramento à fracão $<40 \mu \mathrm{m}$, em peneira de aço inoxidável (DIN 4188); - desidratação por liofilização; e, - desagregação em gral de porcelana.

\section{ANÁLISE}

Para a determinação de $\mathrm{Cr}, \mathrm{Mn}$, $\mathrm{Fe}, \mathrm{Co}, \mathrm{Ni}, \mathrm{Cu}, \mathrm{Zn}$ e $\mathrm{Pb}$ utilizou-se o método da análise seqüencial modificado de TESSIER et al. (1979), que consiste em extrair com seletividade, através de reagentes apropriados, os elementos que possuem afinidade com as seguintes fases do ambiente sedimentar:

- a fase trocável, que compreende os metais adsorvidos nos argilo-minerais, óxidos hidratados de manganês e ferro, ácidos húmicos (mudanças na composição iônica das águas estuarinas, provocam a remobilização destes metais);

- a fase orgânica, que agrupa os metais ligados à matéria orgânica e aos sulfetos (sob condições oxidantes ocorre a degradação da matéria orgânica e, conseqüentemente, os metais traço são removidos para a solução);

- a fase carbonato, que engloba os metais ligados aos carbonatos $(\mathrm{em} \mathrm{pH}$ alcalinos, os metais podem coprecipitar com carbonatos);

- a fase redutível, que reúne os metais ligados aos óxidos de $\mathrm{Fe}$ e $\mathrm{Mn}$ (os óxidos de Fe e Mn são termodinamicamente instáveis sob condições anóxidas, e são excelentes capturadores de metais traços); e,

- a fase residual, que compreende os metais da estrutura mineral (é pouco provável a liberação destes metais num tempo razoável, sob condições naturais).

Assim, as quatro primeiras fases compreendem os metais potencialmente disponíveis no ambiente.

Foram identificadas quatro fases, 
exceto aquela dos metais ligados aos carbonatos, devido às baixas concentrações ou ausência de carbonatos nos sedimentos analisados. As extrações seletivas seguiram o esquema abaixo:

\section{a) cátions trocáveis:}

Em $1 \mathrm{~g}$ de sedimento seco foram adicionados $20 \mathrm{ml}$ de $\mathrm{CH}_{3} \mathrm{COONH}_{4}$ IN (pH 7), seguindo-se uma agitação durante $2 \mathrm{~h}$.

\section{b) cátions ligados à matéria orgânica e aos sulfetos:}

Ao resíduo de (a) foram adicionados $16 \mathrm{ml}$ de $\mathrm{H}_{2} \mathrm{O}_{2} 30 \%+\mathrm{HNO}_{3} 0,02 \mathrm{M}$ $(5 v+3 v)$, ajustado a $\mathrm{pH} 2$. Seguindo-se uma agitação continua por $5 \mathrm{~h}$ e, posteriormente, um aquecimento a $98^{\circ} \mathrm{C}$.

c) cátions ligados aos óxidos e hidróxidos de Mn e Fe:

Ao residuo de (b) adicionaram-se 35 $\mathrm{ml}$ de $\mathrm{NH}_{2} \mathrm{OH} . \mathrm{HCl} 0,1 \mathrm{~N}+\mathrm{CH}_{3} \mathrm{COOH}$ $(25 \mathrm{v}+\mathrm{v})$, que foram agitados durante $4 \mathrm{he}$ posteriormente aquecidos a $98^{\circ} \mathrm{C}$ por $1 \mathrm{~h}$. Para cada extração (a) e (b), adicionaram-se $10 \mathrm{ml}$ de $\mathrm{CH}_{3} \mathrm{COONH}_{4} 3,5 \mathrm{M}$, os quais foram submetidos a $1 \mathrm{~h}$ de agitação. $\mathrm{O}$ resíduo foi primeiro separado por centrifugação a $3000 \mathrm{rpm} / 10 \mathrm{~min}$ e depois, por filtração em Whatman 41.

\section{d) cátions da estrutura mineral:}

$\mathrm{O}$ resíduo do (c) foi digerido em $12 \mathrm{ml}$ da mistura $\mathrm{HF}+\mathrm{HClO}_{4}(5 \mathrm{v}+\mathrm{v})$, de acordo com o procedimento para análise de metal total.

Para essa análise utilizaram-se tubos de polietileno próprios para centrífuga e aquecimento, com todos os metais determinados pelo método da absorção atômica, no aparelho FMD4 ZEISS.

\section{RESULTADOS}

A extração seletiva dos metais das amostras dos canais e do rio Guamá apresenta os seguintes resultados (Tab. 1).

Tabela 1. Concentração média dos metais de transição (em mg. $\mathrm{kg}^{-1}$ ) nas fases geoquímicas dos sedimentos de fundo dos canais de drenagem e do río Guamá, Belém (PA).

\begin{tabular}{ccccccccc}
\hline Fases & $\mathrm{Cr}$ & $\mathrm{Mn}$ & $\mathrm{Fe}$ & $\mathrm{Co}$ & $\mathrm{NI}$ & $\mathrm{Cu}$ & $\mathrm{Zn}$ & $\mathrm{Pb}$ \\
\hline $\begin{array}{c}\text { Trocável } \\
\text { Canais }\end{array}$ & 1,00 & 45,0 & nd & 4,31 & 3,88 & 3,32 & 42,2 & 15,8 \\
$\begin{array}{c}\text { Rio Guamá } \\
\text { Oxidável }\end{array}$ & 1,00 & 192 & nd & 0,17 & 3,64 & 1,00 & 2,61 & 1,00 \\
$\quad$ Canais & 5,13 & 8,35 & nd & 8,21 & 0,86 & 16,9 & 40,6 & 5,13 \\
Rio Guamá & 1,00 & 24,3 & nd & 6,23 & 0,87 & 1,00 & 2,31 & 5,14 \\
Redutível & & & & & & & & \\
$\quad$ Canais & 1,74 & 22,0 & 0,71 & 23,8 & 0,5 & 10,9 & 154 & 71,9 \\
Rio Guamá & 12,1 & 162 & 0,96 & 12,1 & 0,44 & 1,00 & 31,6 & 1,00 \\
Residual & & & & & & & & \\
$\quad$ Canais & 21,5 & 32,3 & 0,27 & 26,4 & 31,3 & 16,5 & 45,6 & 29,7 \\
Rio Guamá & 29,5 & 136 & 0,55 & 29,5 & 33,4 & 6,7 & 48,3 & 34,5 \\
\hline
\end{tabular}

nd- não detectado 
Do total de cromo analisado, nos canais $73,71 \%$ ocorrem associados à fase residual e $17,59 \%$ à oxidável. No rio Guamá, praticamente todo o $\mathrm{Cr}$ se relaciona à fase residual, com $90 \%$ da concentração total, e os outros $10 \%$ se distribuem de forma semelhante dentre as demais fases (Fig. 2).

$O$ manganês relaciona-se preferencialmente à fase trocável. Da concentração total analisada nos canais, $41,80 \%$ e $37,39 \%$ no rio Guamá pertencem a esta fase. As fases redutivel e residual são as próximas formas às quais o $\mathrm{Mn}$ ocorre relacionado. Nos canais, $20,46 \%$ na fase redutivel e $29,99 \%$ na fase residual. No rio Guamá, $31,49 \%$ pertencem à fase redutivel e $26,39 \%$ à fase residual (Fig. 2).

$\mathrm{O}$ ferro é ligado exclusivamente às fases redutível (com $72,86 \%$ no caso dos canais e $63,72 \%$ no rio Guamá) e residual, com $27,14 \%$ nos canais e $36,28 \%$, no rio Guamá (Fig. 2).

Nos sedimentos dos canais, o cobalto não se encontra dominantemente associado à uma única fase. Do total, $42,1 \%$ relaciona-se à fase residual e $37,92 \%$ à fase redutível. No rio Guamá ocorre uma certa preferência à fase residual, com $61,46 \%$ e à fase redutivel, com $25,21 \%$ (Fig. 2).

A distribuição do níquel é muito parecida entre os canais e o rio. Ele predomina na fase residual, com $85,67 \%$ da concentração total nos canais e com $87,09 \%$, no caso do rio Guamá. A próxima forma de ocorrência é na fase trocável, com $10,61 \%$ nos canais e $9,48 \%$, no rio Guamá (Fig. 3).
Entre os elementos analisados, o cobre mostrou uma distribuição relativamente mais equilibrada entre as diversas fases dos sedimentos dos canais, com $35,46 \%$ na fase oxidável, $34,54 \%$ na fase residual e $23,04 \%$ na fase redutível. Por outro lado, no rio Guamá, o Cu ocorre dominantemente associado à fase residual, $\operatorname{com} 73,63 \%$ do total e nas demais distribui-se de forma homogênea (Fig. 3).

Nos sedimentos dos canais, o zinco associa-se predominantemente à fase redutivel, com $54,57 \%$ da concentração total. No restante das fases, o $\mathrm{Zn}$ é distribuido de maneira relativamente homogênea. No rio Guamá, o Zn relaciona-se preferencialmente às fases residual, com $56,94 \% \mathrm{e}$ a redutível com $37,26 \%$ da concentração total (Fig. 3),

O chumbo demonstra uma tendência semelhante ao $\mathrm{Zn}$. Nos sedimentos dos canais, ele se relaciona basicamente à fase redutivel $(58,67 \%$ da concentração total). A fase residual contém $24,21 \%$ de todo o chumbo analisado. No rio Guamá, praticamente todo o chumbo está associado à fase residual, somando $83,66 \%$ da concentração total (Fig. 3).

Finalmente, o manganês que está preferencialmente relacionado à fase residual tanto nos canais (74\%) como no rio Guamá $(68 \%)$.

\section{DISCUSSÃO}

De acordo com os resultados obtidos, a distribuição dos metais nas fases geoquimicas dos sedimentos analisados é a seguinte:

(a) nos canais, a maioria se associa 


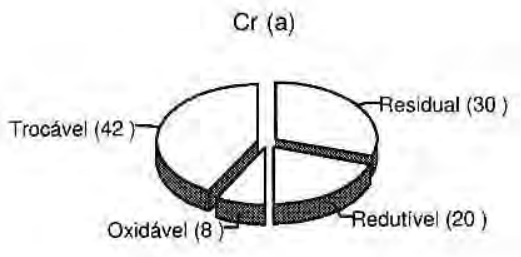

$\operatorname{Mn}(\mathrm{a})$

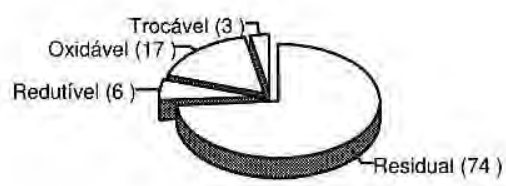

$\mathrm{Fe}(\mathrm{a})$
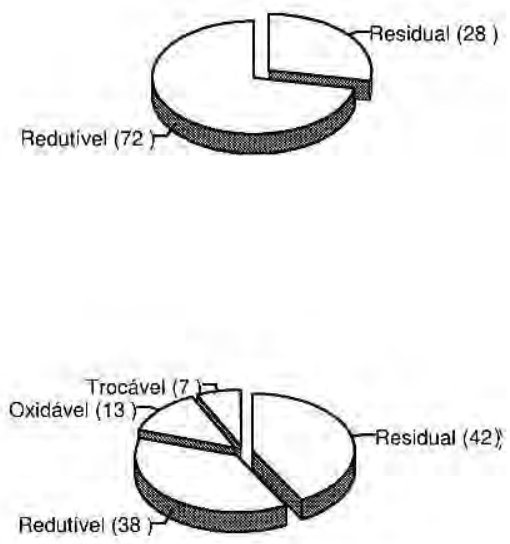

$\operatorname{Cr}(b)$

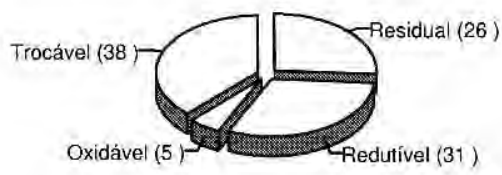

$\mathrm{Mn}(\mathrm{b})$

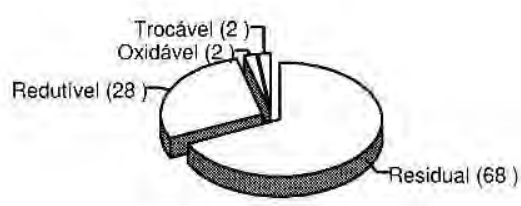

$\mathrm{Fe}(\mathrm{b})$
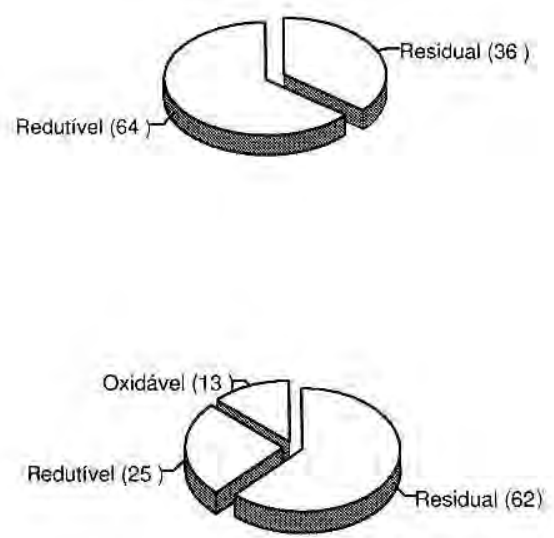

Figura 2. Distribuição de metais ( $\mathrm{Cr}, \mathrm{Mn}, \mathrm{Fe}$ e $\mathrm{Co}$ ) nas diversas fases geoquímiocas dos sedimentos dos canais de Belém (a) e do rio Guamá (b). Entre parenteses valores percentuais. 
$\mathrm{Ni}($ a)

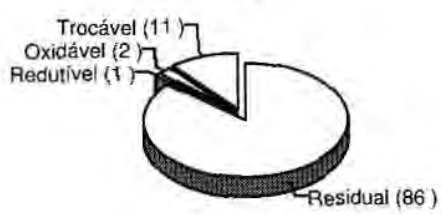

$\mathrm{Cu}(\mathrm{a})$

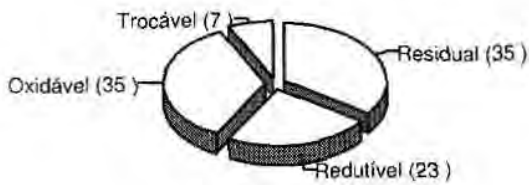

$\mathrm{Zn}(\mathrm{a})$

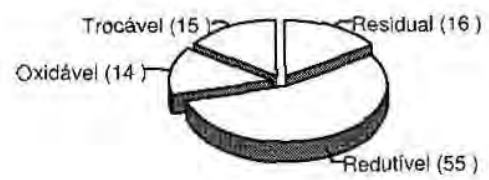

$\mathrm{Pb}(\mathrm{a})$

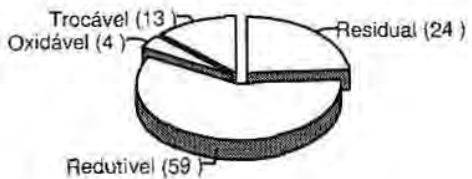

$\mathrm{Ni}(\mathrm{b})$

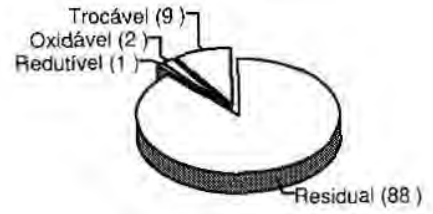

$\mathrm{Cu}(\mathrm{b})$

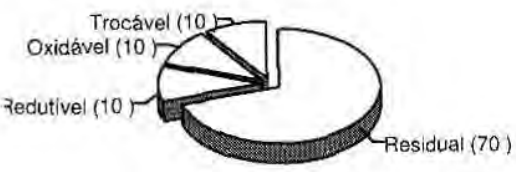

$\mathrm{Zn}(\mathrm{b})$

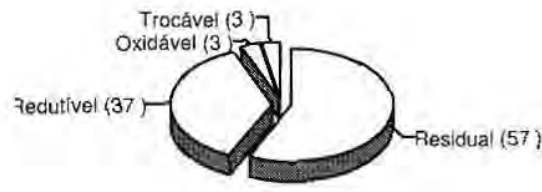

$\mathrm{Pb}(\mathrm{b})$

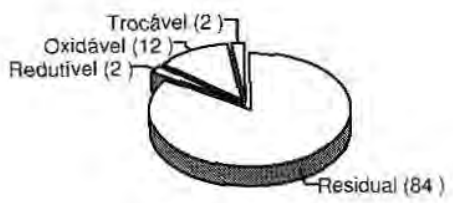

Figura 3. Distribuição de metais ( $\mathrm{Ni}, \mathrm{Cu}, \mathrm{Zn}$ e $\mathrm{Pb}$ ) nas diversas fases geoquímicas dos canais de Belém (a) e do rio Guamá (b). Entre parenteses valores percentuais. 
Canais

Cr

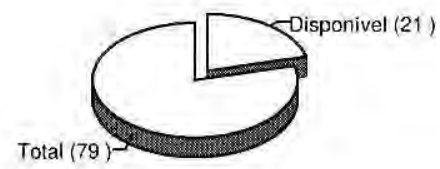

$\mathrm{Mn}$

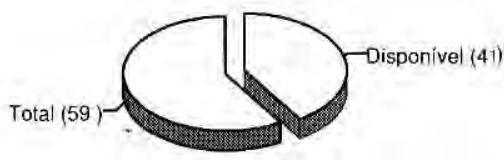

$\mathrm{Ni}$

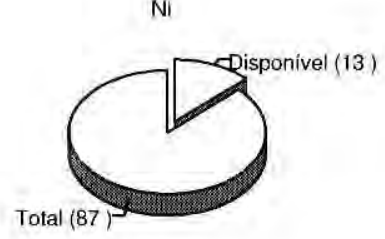

$\mathrm{Fe}$

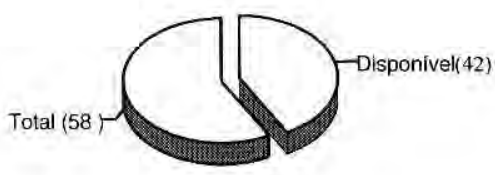

Rio Guamá

$\mathrm{Cr}$

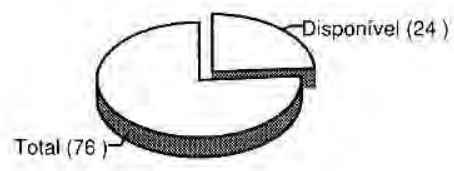

$\mathrm{Mn}$

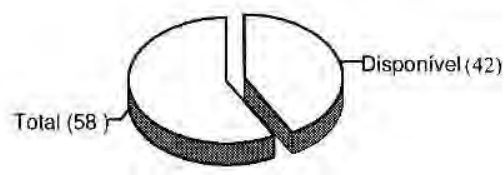

$\mathrm{Ni}$

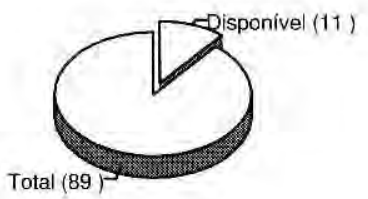

Total $(63)$

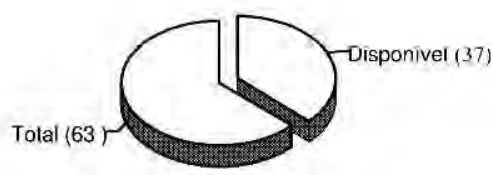

Figura 4a. Distribuição proporcional de metais traço nas frações total e disponivel dos sedimentos dos canais e do rio Guamá. Entre parenteses valores percentuais. 
Co

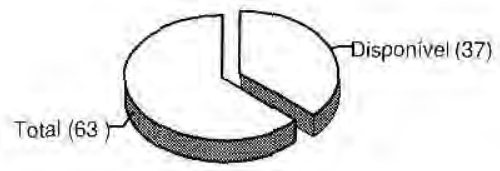

$\mathrm{Cu}$

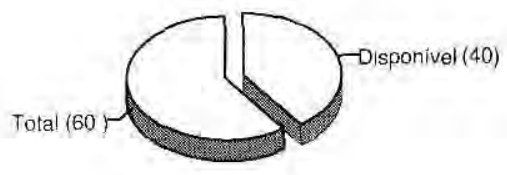

$\mathrm{Zn}$

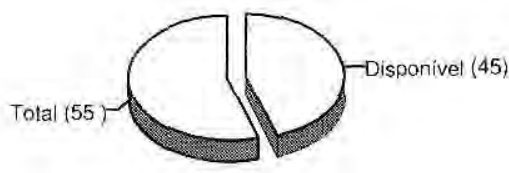

$\mathrm{Pb}$

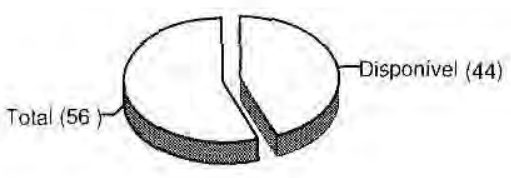

Rio Guamá

Co

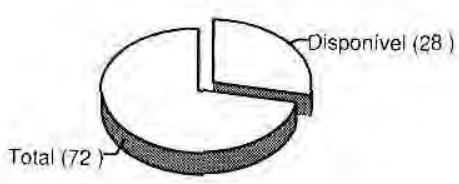

$\mathrm{Cu}$

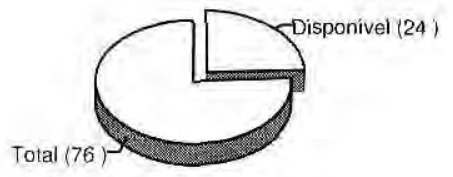

Zn

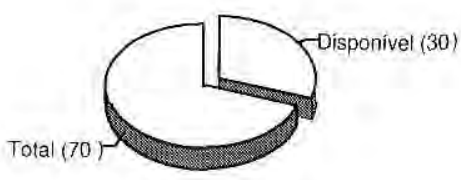

$\mathrm{Pb}$

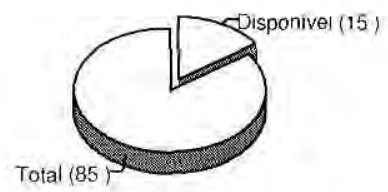

Figura 4b. Distribuição proporcional de metais traço nas frações total e disponivel dos sedimentos dos canais e do rio Guamá. Entre parenteses valores percentuais. 


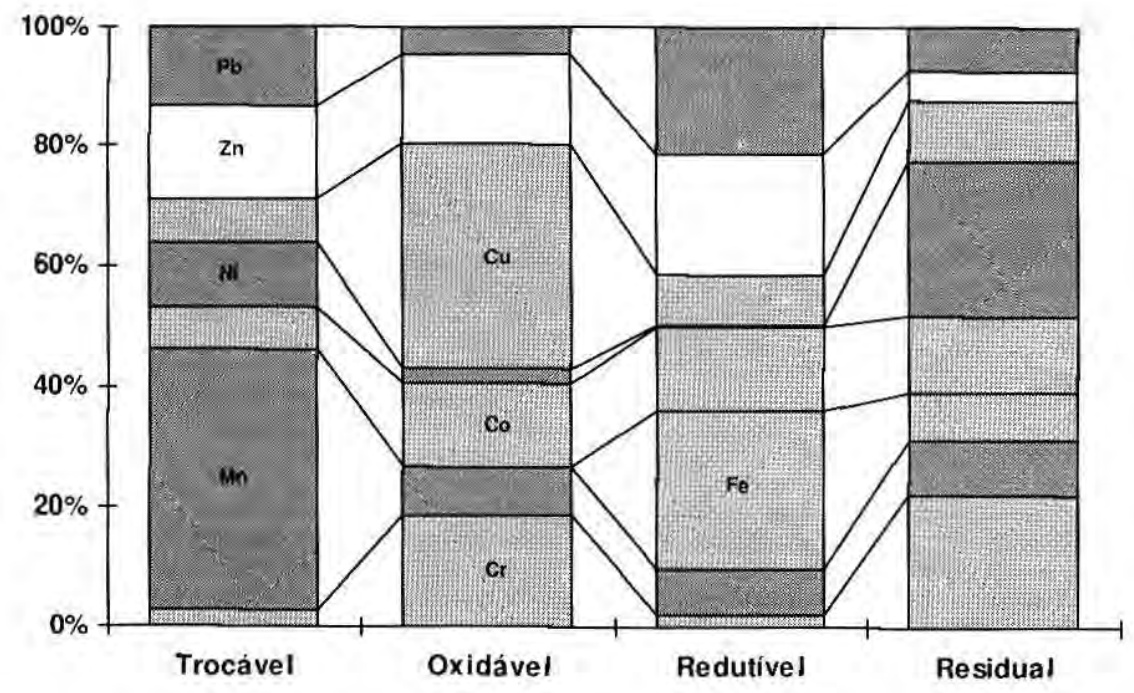

Figura 5a. Distribuição média de metais nas fases geoquimicas dos sedimentos dos canais de Belém.

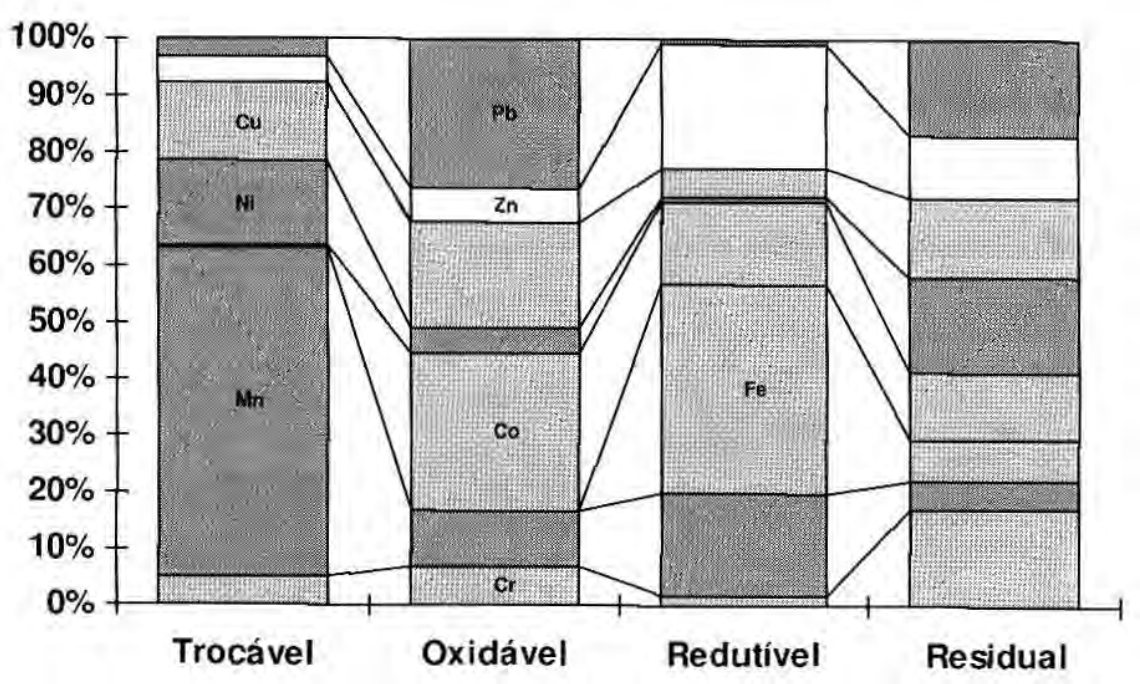

Figura 5b. Distribuição média de metais nas fases geoquimicas dos sedimentos do rio Giuamá. 
preferencialmente às fases redutivel e residual e;

(b) no rio Guamá, a preferência é sobretudo $\therefore$ fase residu ,

A dominância da fase residual, indica que os metais são transportados preferencialmente associados a partículas cristalinas (CHESTER \& STONER, 1975; GIBBS, 1977; TESSIER et al, 1979; LACERDA et al,, 1989; LACERDA et al., 1990), refletindo uma contribuição geoquímica proveniente principalmente do intemperismo das rochas e dos solos locais.

Analisando-se a disponibilidade desses metais entre as amostras dos canais e as do rio Guamá, observa-se a seguinte distribuição (Figs 4a, 4b):

(1) o $\mathrm{Cr}, \mathrm{Mn}, \mathrm{Ni}$ e o $\mathrm{Fe}$ das frações disponivel e total mostram praticamente a mesma proporção tanto nos canais como no rio Guamá e;

(2) o $\mathrm{Co}, \mathrm{Cu}, \mathrm{Zn}$ e o $\mathrm{Pb}$ da fração disponível são proporcionalmente maiores nos canais.

A distribuição dos metais caracteriza-se pela diferente ordem de proporção nos sedimentos dos canais e do rio Guamá, com um único ponto em comum (Figs, 5a, 5b):

(a) o manganês predomina na fase trocável;

(b) o ferro na fase redutível; e,

(c) o cromo, na fase residual.

De um modo geral, existe uma afinidade do $\mathrm{Fe}, \mathrm{Zn}$ e $\mathrm{Pb}$ pela fase redutível e de $\mathrm{Cu}, \mathrm{Cr}, \mathrm{Mn}, \mathrm{Co}$ e $\mathrm{Ni}$, pela residual. Estas relações foram observadas em outras regiões estuarinas (GIBBS, 1977; TESSIER et al., 1979; JORDÃO et al.,
1990; OVALLE et al., 1990).

\section{Bibliografia citada}

CHESTER, R.; STONER, J.H, 1975. Trace elements in sediments from the Lower Severn estuary and Bristol channel. $\mathrm{Ma}$ rine Pollution Bulletin, 6(6):92-96.

GIBBS, R.J. 1977. Transport phases of transition metals in the Amazon and Yukon Rivers. Geological Society of America Bulletin, (88): 829-843.

JORDÃO, C.P.; PEREIRA, J.L.; GOUVEIA, L.C.; PEREIRA, J.C.; BRUNE, W. 1990. Contaminaçào de sedimentos fluviais por metais pesados nas proximidades de uma indústria metalúrgica em Minas Gerais. Geochim. Brasil., 4(1):9-15.

KRAUSKOPF, K.B. 1980. Introdution to geochemistmy. New York, St. Louis, San Francisco. McCraw-Hill, 358p.

LACERDA, L.D.; DE PAULA, F.C.F.; OVALLE, A.R.C.; PFEIFFER, W.C.; MALM, O. 1990. Trace metals in fluvial sediments of the Madeira river watershed, Amazon, Brasil. The Science of the Total Environment, 97/98:525-530.

LACERDA, L.D,; SOUZA, C.M.M.; PESTANA, M.II.D. 1989. Trace metals geochemical associations in sediments of a non-contaminated estuary. Ciència $e$ Cultura, 41(3):301-304.

OVALLE, A.R.C.; BARROSO, L.V.; DE PAULA, F.C.F; ABRÃO, J.J. 1989. Geoquimica de metais pesados nos sedimentos fluviais do sistema lagunar de Maricá-Guarapina, Rio de Janeiro, In: CONGRESSO BRASILEIRO DE GEOQUIMICA, 2., Rio de Janeiro. 1989. Anais. Rio de Janeiro, SBGq.. p.351-356.

TESSIER, A.; CAMPBELL, P.G.G.; BISSON, M.. 1979. Sequential extraction procedure for the speciation of particulate trace metals. Analytical Chemistry, 51 (17):844-851. 